\title{
Long-term consequences of respiratory disease in infancy
}

\author{
W. W. HOLLAND \\ From the Department of Community Medicine, St. Thomas's Hospital Medical School, London \\ P. BAILEY AND J. M. BLAND \\ From the Department of Clinical Epidemiology and Social Medicine, St. George's Hospital Medical School, \\ London
}

SUMMARY In a study of Kent schoolchildren it has been shown that those who had a history of bronchitis under the age of five were more likely to have reported respiratory symptoms at the age of 11 (Bland et al., 1974). After this finding, it was necessary to test whether these differences would continue or diminish as the children grew older. One thousand three hundred schoolchildren in four areas of Kent were studied by physical examination and parental questionnaire at the ages of 5 , 11, and 14. The relative risk of having reported respiratory symptoms for children with a history of early bronchitis, asthma, or pneumonia, compared with other children, was the same at the age of 14 as it was at the age of 11 . These relationships could not be explained by social class effects, and were probably not due to parental bias in reporting.

Respiratory disease in the first years of life has been shown to be associated with respiratory symptoms later (Colley and Reid, 1970; Colley et al., 1973; Bland et al., 1974; Kiernan et al., 1976). In a previous paper (Bland et al., 1974), we compared children who were reported to have had bronchitis, whooping cough, asthma or pneumonia in their first five years with children without such a history. These children were then re-examined at the age of 11-12 years. Children with a history of bronchitis, asthma or pneumonia were reported to have a far higher prevalence of various respiratory symptoms than other children. This association was almost absent for children who had had whooping cough. In this paper, we report on an extension of this study to take into account data from children aged 14.

\section{Method}

The Kent Respiratory Disease Study began in 1964 (Holland et al., 1969a; 1969b). The study population consisted of all children aged 5, 11, and 14 attending local authority schools in four study areas: Tonbridge, Rochester, Malling, and Cranbrook. The basic design has been described. Children were given a routine examination by school medical officers at the ages of 5,11 , and 14, and these examinations provided the setting for collecting information on respiratory disease. The parents of each child attending school in the study areas were asked to complete a simple questionnaire on the child's past respiratory illness and symptoms, respiratory symptoms and illnesses in the last 12 months, and social and home circumstances. The examinations assessed height, weight, and ventilatory function, using a Wright peak flow meter.

In 1970-71, the children who were first examined at the age of 5 , who had by then reached the age of 11, were re-examined. Parents were asked to complete a similar questionnaire on the child's respiratory symptoms and illness in the previous 12 months (Bland et al., 1974).

In 1973-74, when the children were 14 , they were examined for a third time, and again a similar questionnaire was completed by parents.

During this nine-year period many children left the study area and were thus lost to the follow-up. The number present at each stage is shown in Table 1 for each area. Overall, $28 \%$ of the children examined at the age of 5 remained in the study until they were 14. The most stable area was Tonbridge, where almost $42 \%$ remained, and the least stable was Rochester ( $22 \%$ ). Loss to the follow-up was also related to social class. Table 2 shows the composition of the sample by social class; there is a clear trend from the greatest loss in Social Class I to the least loss in Social Class V. The substantial 
Table 1 Number of children in each area at each examination

\begin{tabular}{lcccl}
\hline Area & $\begin{array}{l}\text { 1st exam } \\
\text { (5 years) }\end{array}$ & $\begin{array}{l}\text { 2nd exam } \\
(11 \text { years) }\end{array}$ & $\begin{array}{l}\text { 3rd exam } \\
(14 \text { years })\end{array}$ & $\begin{array}{l}\% \text { remaining } \\
\text { at 3rd exam }\end{array}$ \\
\hline Tonbridge & 816 & 400 & 339 & $41 \cdot 5$ \\
Rochester & 1502 & 538 & 323 & $21 \cdot 5$ \\
Malling & 1362 & 455 & 338 & $24 \cdot 8$ \\
Cranbrook & 1024 & 375 & 319 & $31 \cdot 2$ \\
TOTAL & 4704 & 1768 & 1319 & $28 \cdot 0$ \\
\hline
\end{tabular}

Table 2 Number of children in each social class group at each examination

\begin{tabular}{lrrrl}
\hline Social class & 1st exam & 2nd exam & 3rd exam & $\begin{array}{l}\text { \% remaining } \\
\text { at 3rd exam }\end{array}$ \\
\hline I & 288 & 57 & 42 & $14 \cdot 6$ \\
II & 708 & 197 & 158 & $22 \cdot 3$ \\
III & 2501 & 1017 & 763 & $30 \cdot 5$ \\
IV & 665 & 299 & 221 & $33 \cdot 2$ \\
V & 283 & 144 & 102 & $36 \cdot 0$ \\
Other and & 259 & 54 & 33 & $12 \cdot 7$ \\
not known & 259 & 1768 & 1319 & $28 \cdot 0$ \\
TOTAL & 4704 & & & \\
\hline
\end{tabular}

Table 3 Number of children for whom a history of respiratory illness was reported at first examination, and numbers remaining at subsequent examinations

\begin{tabular}{lcccc}
\hline $\begin{array}{l}\text { Respiratory illness } \\
\text { before age 5 }\end{array}$ & 1st exam & 2nd exam & 3rd exam & $\begin{array}{l}\% \text { remaining } \\
\text { at 3rd exam }\end{array}$ \\
\hline Whooping cough & 579 & 252 & 172 & $29 \cdot 7$ \\
Asthma & 152 & 57 & 42 & $27 \cdot 6$ \\
Pneumonia & 148 & 51 & 33 & $22 \cdot 3$ \\
Bronchitis & 1069 & 403 & 273 & $25 \cdot 5$ \\
TOTAL & 4704 & 1768 & 1319 & $28 \cdot 0$ \\
\hline
\end{tabular}

Table 4 Relative risk (and prevalence \%) of respiratory symptoms at the ages of 11 and 14, associated with a report of bronchitis before the age of $5(N=273)$

\begin{tabular}{|c|c|c|c|c|}
\hline Symptom or diagnosis & Age 11 & & Age 14 & \\
\hline $\begin{array}{l}\text { Bronchitis } \\
\text { Severe colds } \\
\text { Wheezy chest } \\
\text { Morning cough } \\
\text { Cough during the day or at night } \\
\text { Cough for three months } \\
\text { Morning phlegm } \\
\text { Phlegm during the day or at night } \\
\text { Phlegm for three months }\end{array}$ & $\begin{array}{l}5 \cdot 4^{* * *} \\
1 \cdot 4^{* * *} \\
7 \cdot 4^{* * *} \\
3 \cdot 0^{* * *} \\
2 \cdot 5^{* * *} \\
3 \cdot 6^{* * *} \\
3 \cdot 6^{* *} \\
4 \cdot 0^{* * *} \\
2 \cdot 2^{*}\end{array}$ & 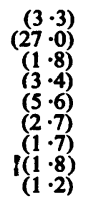 & $\begin{array}{l}5 \cdot 4^{* * * *} \\
1 \cdot 4^{* * *} \\
8 \cdot 5^{* * *} \\
2 \cdot 0^{*} \\
2 \cdot 3^{* * *} \\
4 \cdot 4^{* * *} \\
2 \cdot 4^{*} \\
2 \cdot 8^{*} \\
4 \cdot 3^{* *}\end{array}$ & $\begin{array}{r}(2 \cdot 9) \\
(35 \cdot 5) \\
(1 \cdot 5) \\
(3 \cdot 1) \\
(5 \cdot 3) \\
(1 \cdot 8) \\
(2 \cdot 2) \\
(2 \cdot 2) \\
(1 \cdot 0)\end{array}$ \\
\hline
\end{tabular}

loss in the 'other and not known' group is explained by the large armed services component in this group.

As stated before (Bland et al., 1974), we cannot extrapolate from this sample to any population, so it cannot be used to draw any further conclusions about the relationships between respiratory disease and environmental variables. However, it is possible to compare the incidence of respiratory symptoms at later ages of children with and without a history of respiratory disease at the first examination.

The number of children with a history of respiratory disease at the first examination who remained for the second and third examinations is shown in Table 3. There is no evidence that in terms of respiratory disease the remaining children differ from the original sample. Only children who were examined on all three occasions will be considered.

\section{Results}

The prevalence of respiratory symptoms and illness at the ages of 11 and 14 is shown in Table 4, together with the risk for the 273 children with a history of bronchitis, relative to those without such a history. There were significantly more reports of severe colds at the age of 14 than at the age of 11 ; otherwise the prevalence of illness or symptoms reported for the preceding 12 months was similar for the two ages. The difference in prevalence between boys and girls has been reported previously (Bland et al., 1974). Their relative risks, however, were similar, and results for the two sexes have been combined. Children with bronchitis in the first five years of life were 5.4 times more likely to have bronchitis at the age of 11 , and there was also a significantly greater risk for these children of reporting bronchitis, severe colds, wheeze, cough, and phlegm, both at the age of 11 and at the age of 14 . The relative risks of reporting each symptom were similar for the two ages in almost every case. The greatest relative risk was for wheeze, at the age of 11 and at the age of 14 .

These findings can be compared with those for

Table 5 Relative risk of respiratory symptoms at the ages of 11 and 14 , associated with a report of whooping cough, asthma, or pneumonia before the age of 5

\begin{tabular}{|c|c|c|c|c|c|c|}
\hline Symptom or diagnosis & \multicolumn{2}{|c|}{$\begin{array}{l}\text { Whooping cough }(N=172) \\
\text { Age II }\end{array}$} & \multicolumn{2}{|c|}{$\begin{array}{l}\text { Asthma }(N=42) \\
\text { Age 11 }\end{array}$} & \multicolumn{2}{|c|}{$\begin{array}{l}\text { Pneumonia history }(\mathrm{N}=33 \\
\text { Age } 11\end{array}$} \\
\hline $\begin{array}{l}\text { Bronchitis } \\
\text { Severe colds } \\
\text { Wheezy chest } \\
\text { Morning cough } \\
\text { Cough during the day or at night } \\
\text { Cough for three months } \\
\text { Morning phlegm } \\
\text { Phlegm during the day or at night } \\
\text { Phlegm for three months }\end{array}$ & $\begin{array}{l}0 \cdot 7 \\
0 \cdot 8 \\
2 \cdot 2 \\
0 \cdot 6 \\
1 \cdot 3 \\
1 \cdot 1 \\
2 \cdot \cdot \\
0 \cdot 5 \\
1 \cdot 6\end{array}$ & $\begin{array}{l}1 \cdot 0 \\
1 \cdot 1 \\
1 \cdot 1 \\
0 \cdot 6 \\
0 \cdot 9 \\
1 \cdot 4 \\
1 \cdot 0 \\
1 \cdot 0 \\
0.6\end{array}$ & $\begin{array}{l}4 \cdot 0 * * \\
1 \cdot 9 * * \\
5 \cdot 9 * * \\
4 \cdot 6 * * * \\
3 \cdot 2 * * \\
5 \cdot 2 * * * \\
4 \cdot 7 * * \\
4 \cdot 4^{* *} \\
2 \cdot 0\end{array}$ & $\begin{array}{l}2 \cdot 6 \\
1 \cdot 0 \\
16 \cdot 7 * * * * \\
1 \cdot 5 \\
2 \cdot 3 \\
5 \cdot 9 * * \\
1 \cdot 1 \\
2 \cdot 3 \\
\end{array}$ & $\begin{array}{l}1 \cdot 9 \\
1 \cdot 5 \\
3 \cdot 6 \\
3 \cdot 8 \\
1 \cdot 7 \\
3 \cdot 6 \\
3 \cdot 8 \\
3 \cdot 6 \\
2 \cdot 5\end{array}$ & $\begin{array}{l}5 \cdot 8 * * * \\
1 \cdot 6^{*} \\
7 \cdot 0 * * \\
5 \cdot 4^{* * *} \\
4 \cdot 3^{* * * *} \\
5 \cdot 7^{*} \\
2 \cdot 9 \\
2 \cdot 9 \\
3 \cdot 3\end{array}$ \\
\hline
\end{tabular}

$* \mathrm{P}<0.05 \quad * * \mathrm{P}<0.01 \quad * * \mathrm{P}<0.001$ 
children with a history of various other respiratory illnesses before the age of 5 (Table 5). For whooping cough, no relative risk was significantly greater than 1.0 ; at the age of 11 two symptoms, wheeze and morning phlegm, approached significance; and in the full sample at the age of 11 , these were significant (Bland et al., 1974). At the age of 14, however, these effects had disappeared. Few children with a history of asthma or pneumonia remained in the sample. For asthma, there were significant relationships with most symptoms at the age of 11 , but except for wheeze and chronic cough, these were not as strong at the age of 14 , and failed to reach significance. The small number of asthmatics combined with the generally low prevalence of symptoms and disease makes it impossible to draw many conclusions from these data. The same applies to the effect of pneumonia: the tendency is for a consistently increased risk of symptoms at the ages of 11 and 14, but the errors are likely to be large.

These relationships might perhaps be explained by some other factor, such as housing or nutrition, which varied with social class. Only in Social Class III were there sufficient children with a history of bronchitis to test whether the effect was independent of social class (Table 6). The relationship between early bronchitis and respiratory symptoms at the ages of 11 and 14 remained within this class, although the smaller number of children leads to increased error, and not all the risks were significant.

Table 6 Relative risks of respiratory symptoms at the ages of 11 and 14, associated with a report of bronchitis before the age of 5, for Social Class III only

\begin{tabular}{|c|c|c|}
\hline Symptom or diagnosis & Age 11 & Age 14 \\
\hline $\begin{array}{l}\text { Bronchitis } \\
\text { Severe colds } \\
\text { Wheezy chest } \\
\text { Morning cough } \\
\text { Cough during the day or at night } \\
\text { Cough for three months } \\
\text { Morning phlegm } \\
\text { Phlegm during the day or at night } \\
\text { Phlegm for three months }\end{array}$ & $\begin{array}{l}3 \cdot 6^{* *} \\
1 \cdot 2 \\
4 \cdot 7^{* *} \\
3 \cdot 3^{* *} \\
2 \cdot 0^{*} \\
2 \cdot 5 \\
3 \cdot 5^{*} \\
4 \cdot 4^{* *} \\
2 \cdot 3\end{array}$ & $\begin{array}{l}3 \cdot 5 * * \\
1 \cdot 4 * * \\
7 \cdot 6 * * * \\
1 \cdot 2 \\
1 \cdot 5 \\
4 \cdot 7 * * \\
2 \cdot 5 \\
2 \cdot 1 \\
3 \cdot 5 *\end{array}$ \\
\hline
\end{tabular}

\section{Discussion}

In this study, both the child's symptoms and disease in the preceding 12 months, and past history of respiratory disease, were collected from the parent, although on different occasions. Similar data were obtained in a cross-sectional study of Derbyshire schoolchildren (Banks et al., 1978) but information on current respiratory symptoms was obtained from the children themselves as well as from their parents. Analysis of these data does not suggest that the findings can be explained by differential reporting of symptoms and disease by parents and their children.

We have previously shown that bronchitis, asthma, and pneumonia in the first five years of life are associated with an excess of respiratory symptoms at the age of 11 . This effect is now found still to be present at the age of 14 , with similar relative risks at each age.

One of the problems of a longitudinal study like this is the attrition of the sample. In this study, we were unable to follow up children who had left the area, or the State education system, and we were left with a group which was not representative of the original sample. This means that our relative risks could not be regarded as good estimates of the risk in the general population of schoolchildren. It seems unlikely, however, that the relationship between symptoms and previous disease arose because of differential emigration from the sample: this would have had to imply an interaction between history of respiratory disease, tendency for later symptoms, and probability of leaving the area. We examined the number and type of children referred to schools for the physically handicapped, but this gave no indication of any major difference between our sample and the general population in terms of respiratory illness. Hence, we interpret our data as evidence for a general relationship between early respiratory disease and later respiratory symptoms.

It may be that early bronchitis and later symptoms both result from some other factor. For example, it has been shown that cigarette smoking by parents is associated with an increased risk of bronchitis in the first year of life (Colley et al., 1974), and with respiratory symptoms in childhood (Cameron et al., 1969; Norman-Taylor and Dickinson, 1972; Colley, 1974; Bland et al., 1978). It is impossible to determine the importance of parental smoking in the present data, but further analysis of other data may prove helpful. It is also possible that other variables, such as housing or air pollution, may be responsible. The available evidence suggests, however, that the relationship cannot be explained by social class differences, and it has been shown to exist within widely different areas of residence (Bland et al., 1974).

Several studies have shown evidence of a relationship between early respiratory symptoms and later illness. Colley and Reid (1970) in a retrospective study of 10000 children aged 6-10 years found that those reported by their parents to have chronic cough were 3.4 times more likely to have had bronchitis or pneumonia in the past than children with no such history. Burrows et al. (1977) found that adults who reported a history of childhood 
respiratory trouble had more respiratory symptoms. The differences were greatest in those aged over 45 , and reporting bias cannot be excluded. In a study of 3899 men and women (Colley et al., 1973; Kiernan et al., 1976) a significant increase in cough during the day or at night in winter was found for those aged 20 and 25 who had had respiratory illness in the first two years of life. This effect was independent of cigarette smoking, social class of father, and exposure to air pollution. We have already confirmed the findings of these retrospective studies (Bland et al., 1974). In this paper we have emphasised that these effects do not decrease in magnitude as the children grow older.

Our studies have shown that children who suffer respiratory disease in infancy have an increased risk of respiratory symptoms. This tendency probably continues into adulthood, although this has not yet been fully proved. We must now consider whether preventive action could be taken in infancy, since respiratory illness in the early years of life is so common. Our results have relied solely on reporting by parents, whose perception of bronchitis in their young children may not tally with a doctor's definition. Even medical diagnoses of 'bronchitis', 'pneumonia', or 'asthma' are not based on clear-cut definitions. This, and our lack of knowledge of the natural history of these diseases in the first few years of life, make it impossible at present to determine appropriate preventive measures for respiratory illness in early childhood. Further work in this field seems essential.

We thank the children and their parents for their co-operation, and the staff of Kent County Council in the health and teaching services, particularly Dr. A. Elliott. Thanks are also due to past members of the study team, Mr. H. S. Kasap, Mr. T. Halil and Professor A. E. Bennett, to Mr. R. Harris, Miss A. Clark, and Miss V. M. Pollard, statistical assistants, and to Mrs. J. Rowland. This work was supported in part by a grant from the Department of Health and Social Security.

Reprints from W. W. Holland, Professor of Clinical Epidemiology and Social Medicine, Department of Community Medicine, St. Thomas's Hospital Medical School, London SE1 7EH.

\section{References}

Banks, M. H., Bewley, B. R., Dean, J. R., and Pollard, V. M. (1978). Long-term study of smoking by secondary schoolchildren. Archives of Disease in Childhood, 53, 12-19.

Bland, J. M., Bewley, B. R., Pollard, V. M., and Banks, M. H. (1978). Effect of children's and parents' smoking on respiratory symptoms. Archives of Disease in Childhood, 53, 100-105.

Bland, J. M., Holland, W. W., and Elliott, A. (1974). The development of respiratory symptoms in a cohort of Kent schoolchildren. Bulletin of Physiopathological Respiration, 10, 699-716.

Burrows, B., Knudson, R. J., and Lebowitz, M. D. (1977). The relationship of childhood respiratory illness to adult obstructive airways disease. American Review of Respiratory Disease, 115, 751-760.

Cameron, R., Kostin, J. S., Zaks, J. M., Wolfe, J. H., Tighe, G., Oselett, R., Stocker, R., and Winton, J. (1969). The health of smokers' and non-smokers' children touching also on parental influence. British Journal of Preventive and Social Medicine, 14, 28-34.

Colley, J. R. T. (1974). Respiratory symptoms in children and parental smoking and phlegm production. British Medical Journal, 2, 201-204.

Colley, J. R. T., Douglas, J. W. B., and Reid, D. D. (1973). Respiratory disease in young adults: influence of early childhood lower respiratory tract illness, social class, air pollution, and smoking. British Medical Journal, 3, 195-198.

Colley, J. R. T., Holland, W. W., and Corkhill, R. T. (1974). Influence of passive smoking and parental phlegm on pneumonia and bronchitis in early childhood. Lancet, 2, 1031-1034.

Colley, J. R. T., and Reid, D. D. (1970). Urban and social origins of childhood bronchitis in England and Wales. British Medical Journal, 2, 213-217.

Holland, W. W., Halil, T., Bennett, A. E., and Elliott, A. (1969a). Factors influencing the onset of chronic respiratory disease. British Medical Journal, 2, 205- 208.

Holland, W. W., Halil, T., Bennett, A. E., and Elliott, A. (1969b). Indications for measures to be taken in childhood to prevent chronic respiratory disease. Milbank Memorial Fund Quarterly, 47, 215-227.

Kiernan, K. E., Colley, J. R. T., Douglas, J. W. B., and Reid, D. D. (1976). Chronic cough in young adults in relation to smoking habits, childhood environment and chest illness. Respiration, 33, 236-244.

Norman-Taylor, W., and Dickinson, V. A. (1972). Dangers for children in smoking families. Community Medicine, 128, 32-33. 